\title{
A CASE OF INAPPROPRIATE ANTIDIURETIC HORMONE SECRETION SYNDROME ASSOCIATED WITH COVID-19 PNEUMONIA
}

\author{
E. Gemcioglu ${ }^{1, *}$, B. Karabuga ${ }^{3}$, A. $\operatorname{Ercan}^{1}$, A. $\operatorname{Erden}^{2}$ \\ Ankara City Hospital, Ministry of Health, ${ }^{1}$ Department of Internal Medicine, ${ }^{2}$ Division of Rheumatology, \\ 3 "Yildirim Beyazit" University, Faculty of Medicine - Internal Medicine, Ankara, Turkey
}

\begin{abstract}
At the end of 2019, a novel coronavirus was identified as the cause of a cluster of pneumonia in China and it spread quickly to other countries. Although Covid-19 causes severe pneumonia, it is known that it can be associated with different diseases and prognosis of disease can be due to many of disorders such as hyponatremia.

A 65-year-old female patient with sarcoidosis, cronic obstructive lung disease, hypertension and congestive heart failure presented to the emergency department with shortness of breath and fever. Oropharyngeal swab for Covid-19 PCR test was positive. After the initiation of treatment, the patient developed hyponatremia.

This case is remarkable because there is no reported case of Covid-19 and inappropriate ADH syndrome coexistence and it demonstrates that there may be a correlation between Covid-19 infection prognosis and hyponatremia.
\end{abstract}

Key words: Inappropriate Antidiuretic Hormone Secretion Syndrome (SIADH), Covid-19.

\section{INTRODUCTION}

A 65-year-old female patient with sarcoidosis, chronic obstructive lung disease, hypertension and congestive heart failure with preserved ejection fraction (ejection fraction was 55\%) presented to the emergency department with shortness of breath and fever. She had no history of known COVID-19 exposure. She had no fever when she applied to hospital, her oxygen saturation of $94 \%$ while she was breathing ambient air; no tachypnea, blood pressure was elevated as $150 / 90 \mathrm{mmHg}$, heart rate was normal (80 per minute).

Laboratory tests showed normal kidney, thyroid, liver function tests. Serum $\mathrm{Na}$ level was $134 \mathrm{mEq} / \mathrm{L}$, serum glucose level was $73 \mathrm{mg} / \mathrm{dL}$, serum osmolality was normal as $295 \mathrm{mOsm} / \mathrm{kg}$, white blood cell level: $8.24 \times 10^{9} / \mathrm{L}$, hemoglobin: $12.0 \mathrm{~g} / \mathrm{dL}$ lymphocyte level was decreased $0.39 \times 10^{9} / \mathrm{L}$ platelet level was normal as $205 \times 10^{9} / \mathrm{L}$, d-dimer, sedimentation level and C-reactive protein were elevated as $1.13 \mathrm{mg} / \mathrm{L}, 47 \mathrm{~mm} / \mathrm{h}$ and $0.020 \mathrm{~g} / \mathrm{L}$ respectively. Ferritin and procalcitonin levels were normal as $40 \mu \mathrm{g} / \mathrm{L}$ and $<0.03 \mu \mathrm{g} / \mathrm{L}$ respectively. Oropharyngeal swab for COVID-19 PCR test was positive. Chest computed tomography showed chronic fibrotic modifications due to chronic pulmonary diseases and peripherally located ground-glass opacities in lungs bilaterally (Fig. 1). The patient was admitted to hospital and began to receive treatment with hydroxychloroquine, azithromycin, favipiravir and low molecular weight heparin. One day after the initiation of treatment, it was seen that $\mathrm{Na}$ level was decreased to $124 \mathrm{mEq} / \mathrm{L}$. Control $\mathrm{Na}$ level test was performed and it was seen that $\mathrm{Na}$ level was continuing to decrease to $118 \mathrm{mEq} / \mathrm{L}$. Spot urine sodium $(\mathrm{Na})$ level, spot urine osmolality and serum plasma osmolality tests were performed, and it showed increased spot urine sodium as $68 \mathrm{mEq} / \mathrm{L}$, increased spot urine osmolality as $203 \mathrm{mOsm} / \mathrm{kg}$, decreased serum plasma osmolality as $243 \mathrm{mOsm} / \mathrm{kg}$. According to results, the patient was diagnosed as inappropriate ADH secretion syndrome. In the following days, clinical situation of patient worsened, and the patient was intubated. The amount of fluid the patient received daily was limited to $1000 \mathrm{cc}$. An increase in sodium values was observed with fluid restriction. On the second day of fluid restriction therapy, $\mathrm{Na}$ level increased to $128 \mathrm{mEq} / \mathrm{L}$. It is known that COVID-19 infection presents with severe pneumonia that causes acute respiratory distress syndrome. Currently, it is also known that it can be associated with many of syndromes or diseases. Hyponatremia was common in patients with COVID-19, and there was a correlation with the degree of renal injury (1). In our case, hyponatremia of patient with COVID-19 pneumonia associated with SIADH. Although SIADH can be seen associated with lung diseases such as pneumonia

*Correspondence to: Emin Gemcioglu MD, Ankara City Hospital, Ministry of Health, Department of Internal Medicine, Üniversiteler, Bilkent Blv. No.1, 06800, Çankaya, Ankara, 06105, Turkey, E-mail: egemcioglu@ gmail.com 

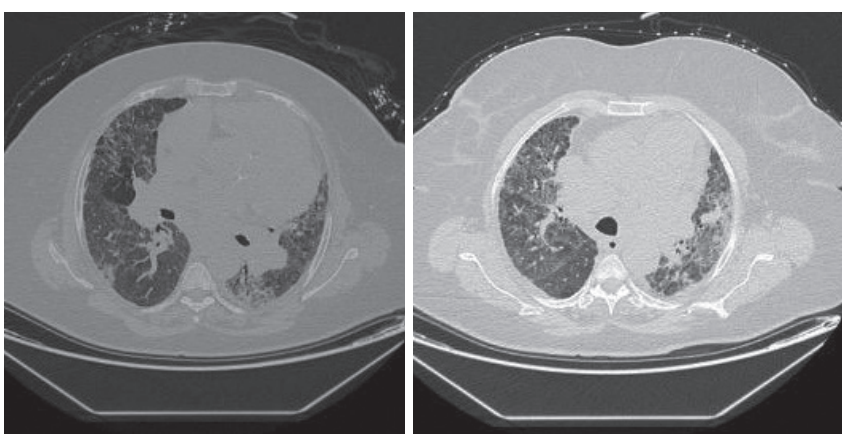

Figure 1. Chronic fibrotic modifications due to chronic pulmonary disease and peripherally located ground glass opacities both of right and left lungs.

and lung cancer, it has not been reported that SIADH associated with COVID-19 infection. COVID-19 infection may involve the regulatory pathway of antidiuretic hormone (ADH) secretion. The syndrome of inappropriate secretion of antidiuretic hormone is a disorder of impaired water excretion caused by the inability to suppress the secretion of antidiuretic hormone (3). This syndrome can appear due to many of reasons such as drugs (selective serotonin reuptake inhibitors, anticancer drugs, etc.), surgeries, central nervous system disorders, malignancies (small cell lung cancer), pulmonary disease particularly pneumonia (viral, bacterial, tuberculosis) (2-6). In our case, SIADH can be due to pneumonia but hyponatremia had developed after the initiation of treatment with hydroxychloroquine, azithromycin, favipiravir and low molecular weight heparin, so these medications may have contributed to SIADH. There is no reported evidence about hydroxychloroquine or favipiravir and SIADH. While the proof of a direct involvement of COVID-19 is absent, we hypothesize that the virus was responsible for this SIADH. First, the SIADH occurred in the wake of proven COVID-19 infection. Secondly, human coronaviruses can also present with neuroinvasive properties which may have led to SIADH (7). The diagnostic criteria of SIADH are decreased serum sodium level and serum plasma osmolality, increased urine sodium concentration and urine osmolality, normovolemic situation, without recent use of diuretics, normal kidney, liver, heart and endocrinological features. In our case, despite our patient had congestive heart failure diagnosis, she was normovolemic and her ejection fraction was $55 \%$, she had normal kidney and liver, endocrinological function tests and there was no recent use of diuretic medication. Although early renal injury was common in patients with COVID-19 and it was reported that there is a correlation between hyponatremia and kidney injury, our patients' kidney functions did not worsen but pulmonary symptoms worsened, and she was intubated in her follow up. According to these findings, there may be a correlation between hyponatremia and poor prognosis. SIADH can be seen in patients that suffer from many diseases, particularly pulmonary diseases. This case is remarkable because there is no reported case of COVID-19 and inappropriate ADH secretion syndrome coexistence in the literature and also it demonstrates that there may be a correlation between COVID19 infection prognosis and hyponatremia, so more studies are needed to prove this hypothesis.

\section{Conflict of interest}

The authors declare that they have no conflict of interest.

\section{References}

1. Hong X, Chi Z, Liu G, Huang H, Guo S, Fan J, Lin X, Qu L, Chen R, Wu L, Wang L, Zhang Q, Wu S, Pan Z, Lin H, Zhou Y, Zhang Y. Analysis of early renal injury in COVID-19 and diagnostic value of multi-index combined detection. MedRxiv 2020.03.07.20032599: 1-23.

2. Rose BD, Post TW. Clinical Physiology of Acid-Base and Electrolyte Disorders, $5^{\text {th }}$ ed, McGrawHill, New York. 2001:703761.

3.Johnson BE, Chute JP, Rushin J, Williams J, Le PT, Venzon D, Richardson GE. A prospective study of patients with lung cancer and hyponatremia of malignancy. Am J Respir Crit Care Med. 1997; 156(5): 1669-1678.

4. Weissman PN, Shenkman L, Gregerman RI. Chlorpropamide hyponatremia: drug-induced inappropriate antidiuretic-hormone activity. N Engl J Med. 1971; 284(2): 65-71.

5. Fieldman NR, Forsling ML, Le Quesne LP. The effect of vasopressin on solute and water excretion during and after surgical operations. Ann Surg. 1985; 201(3): 383-390.

6. Anderson RJ. Hospital-associated hyponatremia. Kidney Int. 1986; 29(6): 1237-1247.

7. B. Gu J, Gong E, Zhang B, Zheng J, Gao Z, Zhong Y, Zou W, Zhan J, Wang S, Xie Z, Zhuang H, Wu B, Zhong H, Shao H, Fang W, Gao D, Pei F, Li X, He Z, Xu D, Shi X, Anderson VM, and Anthony S.-Y. Leong. Multiple organ infection and the pathogenesis of SARS. J Exp Med. 2005;202(3): 415-424. 